\title{
Inappropriately Disclosed Default Option May Promote Anti-environmental Behaviors with a Pro-environmental Justification
}

\author{
Guanyi Wang ${ }^{1, *}$ Baoyuan $\mathrm{Ou}^{1, \mathrm{a}}$, Tong Xiao ${ }^{1, \mathrm{~b}}$
}

\author{
${ }^{I}$ Shenzhen College of International Education, China \\ *Guanyi Wang.Email: s16047.wang@stu.scie.com.cn \\ ${ }^{a}$ Baoyuan Ou. Email: s16019.ou@stu.scie.com.cn \\ ${ }^{b}$ Tong Xiao. Email: s16062.xiao@stu.scie.com.cn
}

\begin{abstract}
Default options with a disclosed lofty purpose have been found to be effective for nudging pro-environmental behaviors. However, when the unconscious processing of the default option and the overt processing of disclosure are in conflict, they may produce certain dissonance. To discover such possibility, we manipulated the reality of the default options and the disclosed purposes (environmental protection) to be either matched (set a pro- environmental option as default) or mismatched (set an anti-environmental option as default). Using a questionnaire formatted as a milk tea order leaflet, we collected the responses from 208 high school students towards their selection of straw (proenvironmental default) and package (anti-environmental default). We also ask for their reasons of choice in order to unearth the psychological trade-offs when making the decision. We discovered a baseline default effect which is further amplified by the lofty disclosure, regardless of the type of default-disclosure pairing. The reasons given by participants buttress an unconscious pathway of decision making induced by the presence of undisclosed default option, as people choosing the pro-environmental default do not ascribe their behavior as pro-environmental (disclaimed hero effect). By contrary, people tend to resolve their cognitive dissonance after disclosure by a hypocritical pro-environmental claim. Finally, the implication of this work on market supervision of government was discussed.
\end{abstract}

Keywords: consumer research, defaults, disclosure, pro-environmental behavior, perceived appropriateness, cognitive dissonance, market supervision

\section{INTRODUCTION}

In recent years, many findings of human judgment and decision making are used to cultivate proenvironment behaviors. First, there are some easily perceived promotions such as giving incentives to citizens [1]. These include positive rewards such as providing cash for purchasing green-energy-driven cars, as well as the negative "punishment" like setting higher price per unit volume of gasoline [2]. Another interesting form of incentive is competition. Some cities and universities invented certain competitions of "who will use the least water" or "which dormitory is the most energy-conserving" to elevate the pro-environmental consciousness. It was proven that competition is indeed a very practical promotion [3]. Apart from the approaches listed above, some imperceptible methods are also utilized to help with pro-environmental campaigns, for example, social modeling and convenience. Normative social influence, which means that individuals tend to follow the action of others, is an important component of social modeling. In 2008, Nolan indicated that the conservational act to save energy was more likely to be conducted when the neighbor had done so to present their behavior as a form of the descriptive norm [4]. Besides, convenience is regarded as a specific way to increase easiness to act pro-environmentally. However, the approaches mentioned above are resource-demanding, in which the government would take the risk of enormous investment in several supportive programs that could finish poorly due to draining of budget or lack of strength in the promotion. 
Seeking alternatives, psychologists start to realize the importance of covert persuasion which outweighs the traditional methods in terms of cost-effectiveness and outcome. This can be done through an insensible mechanism, the default effect(with the default option included, the decision-makers are inclined to choose it), imposing a nudge to people and guiding them to act proenvironmentally.

A considerable amount of studies stated the exciting theory that we are very likely to make decisions to the benefit of the question designer unconsciously by virtue of the default option. The default effect, in combination with product displacement or celebrity endorsement, are already popular economic techniques prevalently used as covert marketing for many years [5], which marketers used to urge consumers to purchase costly products or to be involved in the programs and memberships they introduce. For example, Fowlie investigated the default effect when selecting the pricing plan of electricity, using an opt-in and opt-out frame [6]. The result indicated that the opt-out option, which required decision-makers to engage in the project unless they choose to give up, promoted $70 \%$ more participants in accepting this pricing plan than opt-in(the decisionmaker will be excluded from the event unless they choose to be 'in'). In this case, the opt-out frame is the use of the default effect to induce more customers to select the recommended option. Apart from marketing, other areas also utilize this convenient psychological tool. Typically, we are unaware that medical policies largely rely on the default effect, for instance, the countries that adopted an opt-out strategy for organ donation appeared to have a much higher consent rate than those executing the opting-in scheme, with an average difference of $82.3 \%$ [7]. Therefore, the default effect is utilized by both merchants who want to pursue more profit from consumers and by governments to have more citizens aided. Moreover, the default is also used to help patients choose the appropriate insurance plan by employing automatic computational design [8]. The combination of data-processing technology and the default option mitigates inconvenience in decisionmaking, encouraging a higher percentage of patients to select this medical program.

When the default effect is applied to a proenvironmental situation, it also implicitly urges society to protect the natural system. Jorge and Carmelo stated that the pro-environmental default was preferred by the consumers over other default options concerning only pure financial market since it was overall benefiting the society, while the economic market may take advantage of consumers [9]-[10]. In their study, a field experiment was conducted employing the opt-in and opt-out frames mentioned by Fowlie, in order to test the effect of default by measuring the number of participants that were willing to pay more for a carbon-reducing program compensating the carbon release by their airline travel.
Opt-in involves adding an extra amount to the original cost, conversely, opt-out means to deduct the same amount from the previously set price. Though the extent of the effect varies with the value of extra price, the nudging effect is pervasive as the opt-out frame encouraged more participants to choose the default option to offset their carbon release [10].

Several researchers further validated the effectiveness of pro-environmental default. Pichert designed a virtual situation of choosing between an expensive "green energy" provider and another "grey energy" provider that will save money for the consumer, using the same opt-out frame. The result illustrated that a greater percentage of people were willing to purchase "green energy" if it was set as the default [11]. The loss aversion of citizens induced by the default option exceeded the unwillingness to pay, therefore the default effect functioned properly to advocate environmentally friendly companies [12]. Similarly, it was proven that the users were inclined to accept the default option CFL(Compact fluorescent lamp) which consumed much less energy than cheaper incandescent light, resulting in a pro-environmental act [13]. To conclude, the default option does largely endorse pro-environmental actions.

Despite its versatility, the use of the default effect is questioned by critiques, especially when many use it covertly. This elicits ethical issues as consumers are typically unaware of the situation they are in so that their persuasive knowledge is circumvented [14], impeding them to achieve their own marketing goal. The covert marketing strategies also violate the policy against deception proposed by the Federal Trade Commission since they deliberately attempt to alter the purchasing behavior of a rational consumer [15]. Consumers prefer more explicit marketing techniques, protesting for at least a disclosure of the presence of such marketing attempts, and there are several consumer boycotts against those brands using stealthy marketing techniques [16].

A reason behind this unclaimed use of default effect as a covert marketing technique is the belief of many researchers, that this effect would diminish when it is disclosed [17]-[19], similar to many other socialpsychological effects, since people naturally resist detectable threats to their free will of making the decision [20]. Therefore, most marketers are reluctant in giving up the advantages of covertness, and several studies do demonstrate a correction from consumers following the disclosure which reduces the effect of nudging.

However, a recent study found that the disclosure of the good intention of a default setting may surprisingly enhance the default effect in the pro-environmental context. Particularly, if the effectiveness of the default technique is disclosed along with the intention, there seems to be an additional positive effect in selecting the 
default option [21]. This study further suggested that government should enact the pro-environmental policies centered around nudging even if the ex-ante acceptability is low, since public acceptability would increase greatly after implementation when its practicability is conveyed. From the perspective of environmentalists, the perceived effectiveness of default is usually linked with acceptability [22]. This implies that after the disclosure of the nature of the default option and its effectiveness towards environmental protection, no matter by words [22] or by a convincing experience like arbitrarily enacting the policy [21], people can establish a rapport with the initiator of covert actions, thus consciously support his/her choice architecture rather than offended by their persuasion [23]. As a result of this rapport, a study also showed that consumers accepted a smaller discount for an inconvenient pro-environmental option when its systemic benefit was disclosed, evoking not only a higher percentage to select the default option, but also generally higher awareness towards environmental concerns, hence boosting the pro-environmental default option selection.

Why disclosure can sometimes improve default option selection, and impair the effect in other circumstances? There's no systemic best answer for this question. One possible explanation is that different default option settings may have different levels of "perceived appropriateness" among the studies. Perceived appropriateness is defined as whether the tactics of the choice architect seem to be aligned with moral or normative belief [24]-[25]. There is an example in the public service domain, in which the smokers would react more negatively to an antismoking nudge after disclosure, since the central idea conveyed went against their habits, which decreased their perceived appropriateness for the nudge [26]. Another experimental evidence is under a commercial context, in which 2 brands selling macaroni and cheese propagated their products with covert advertisements in a radio show. The presence of covert marketing was either disclosed or not disclosed, and at the end, participants would evaluate the brands in terms of likability and affability, ratings on a 9 point scale, whereas their perceived appropriateness was also measured by rating [27]. The study illustrated that when covert marketing was disclosed, the negative impact on brand evaluation would be insignificant if the perceived appropriateness is high. This experiment portrayed the role of perceived appropriateness in moderating degree and even direction of disclosure effect on covert marketing techniques. Nevertheless, this research is not conclusive, because the source of their perceived appropriateness was inexplicable solely by ratings, and this practice allowed self allocation of participants into different levels of appropriateness. Moreover, it did not consider actual behavioral consequences coupled with brand evaluation, such as purchasing behavior or willingness to recommend, lacking ecological validity. This evidence is also insufficient to generalize the findings of disclosure effect to other nudging techniques, in our case, the effect on selection default option. Specifically, the default setting could be perceived as more intrusive than advertisements in terms of threatening the freedom of consumers to make their decision.

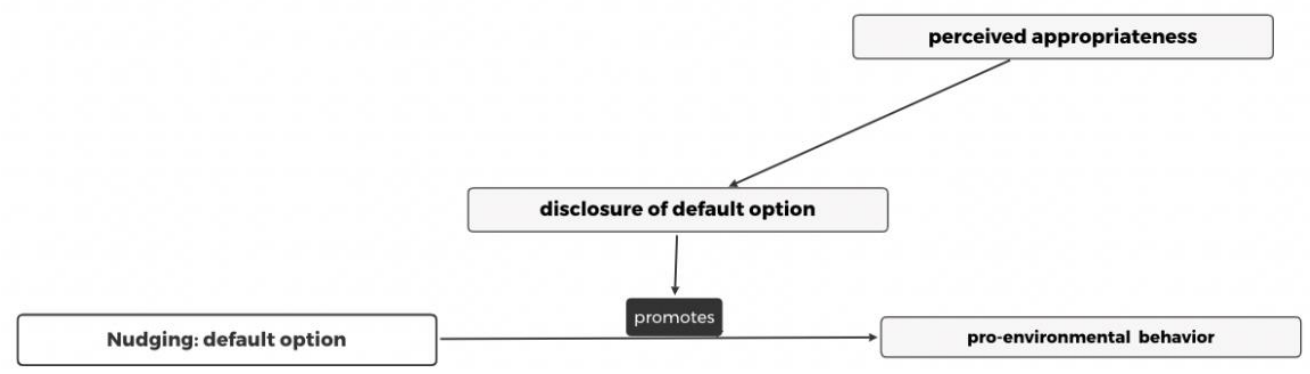

Figure 1 Framework

The disclosure effect on default setting moderated by perceived appropriateness could be better examined if the appropriateness is rigorously manipulated and if participants' selections can lead to immediate feedback. To explore this concept, it's essential to set up high appropriateness and low appropriateness situations respectively and verify alternative underlying mechanisms by investigating the reason behind their choice. It's safe to assume that the pro-environmental default option would elicit higher perceived appropriateness, given the global environmental protection urgency. Whereas any commercial attempts through the default option can mitigate the appropriateness by arising marketplace metacognition of participants [28]. Comparing the direction of disclosure effect under such two circumstances in a real-life context should be able to reach the ultimate conclusion about the moderating role of perceived appropriateness in the selection of default options.

We decide to firstly examine the default effect in the context of promoting pro-environmental behavior in this 
research paper (H1), and we would like to further explore the consequence of disclosing the proenvironmental intention of the default setting, as mentioned before [29]. We assume that there will be a highly supportive attitude generated by disclosure when the perceived appropriateness is high, and this perception could be transformed into actual behavioral outcomes, enhancing the default effect as more participants are willing to conform with the choice architecture(H2). In this case, the behavioral outcomes can be easily measured by purchasing frequency of the consumer.

H1: More participants will stick to the proenvironmental default option compared to the nondefault option because of the default effect.

H2: When the pro-environmental role of the default setting is disclosed, more participants would choose the default option compared to the number of participants choosing the same default option when they are not disclosed.

On the other hand, we notice that the positive disclosure effect is nullified when nudging lacks perceived appropriateness [26], and this could negatively influence the attitude of consumers towards marketers. Previous literature hinted that even though the content of disclosure was unvaried, the perceived intention of the choice architecture would profoundly predominate the direction of the disclosure effect. Considering our disclosure about environmental benefits, it is reasonable to presume that when the choices offered by the vendor become irrelevant to environmental protection and focus on his own marketing goals instead, consumers will have a significantly reduced perceived appropriateness that mitigates the default effect(H3). We name this condition with low perceived appropriateness the hypocritical condition, since the content of disclosure is deliberately altered to disguise the actual intention of the vendor. In this way, the psychological contract between consumers and the hypocritical marketer might be broken, leading to adverse effects like negative impression [30], disappointment, and the sudden decline of trust especially when a rapport has existed previously when consumers once have the notion of an environmentally friendly brand. Ideally, not only that the baseline preference of the default option would diminish in this case, but also that a backfire effect on the default option would be created [28], decreasing its selection. Overall, in the hypocritical condition, the pro-environmental disclosure would be coupled with the default option with exceptional price but nothing stands out in terms of environmental friendliness compared to alternatives.

H3: With the same disclosure as in H2(nonhypocritical), if the following decision is irrelevant to the pro-environmental claim(hypocritical), fewer participants would choose the more expensive default option compared to the number of participants choosing the same default option when they are not disclosed.

Therefore, we plan to conduct an experiment and test our 3 hypotheses. We adopt a milk-tea selling scenario, aiming to target the student consumers specifically. All of the choice architectures are incorporated within a typical milk tea order, involving an environmentally-related choice between paper straw and plastic straw (for H2) and the choice of packaging between expensive cooler bag and cheaper plastic bag, which are both considered source of pollution, indicating their irrelevance in environmental protection(for H3). Additionally, the thermal bag is deliberately priced higher than expected to reveal the hypocritical intention of the marketer more obviously. Both the thermal bag and the paper straw will be the default option, and when the disclosure is absent, the baseline default effect is also examined(for $\mathrm{H} 1$ ).

\section{EXPERIMENT}

\subsection{Method}

\subsubsection{Participants}

In total, 208 people took part in this study, after the elimination of participants who did not follow the instruction, there were in total 179 participants.

\subsubsection{Experimental Design}

In this study, we used a 2 (default vs. non-default, a between-subject factor) $\times 2$ (disclosure vs. nondisclosure, a between-subject factor) $\times 2$ (hypocritical vs. non-hypocritical, a within-subject factor) mixed design. The participants will be randomly allocated to one of the four between-subject conditions and all of them had to make choices in a hypocritical frame and a nonhypocritical frame respectively.

\subsubsection{Materials}

All participants were asked to view a leaflet with six pictures of beverage on it, which resembled those used by common milk-tea stores for the customers to order beverages.

After choosing the drink, they were asked to choose either a paper straw (pro-environmental) or a plastic one (anti-environmental), which was the non-hypocritical setup. Then, they were asked to choose between a cooler bag that could preserve the freshness of drinks and a plain plastic bag, which was the hypocritical setup. A line below the option of paper straw stating "paper straws may slightly affect the drinking experience by an uncomfortable texture" served to remind the customers that paper straws may soften and affect the taste and 
texture of the drink, ensuring the establishment of a trade-off.

In the disclosure condition, the participants received a menu with a red line stating "The default option may affect the decision of people, and we aim to encourage people to protect the environment". And in the 'non-disclosure' condition, this red line was not shown (see Figure 2).

In the non-default condition, neither option was set as the default option. In the default condition, the paper straw and the thermal bag were set as the default options by including an already-filled solid bulb. See figure 3 to view the difference.

\section{Default condition}

\begin{tabular}{|c|c|}
\hline $\begin{array}{l}\text { Please choose the straw: } \\
\text { Paper straw(default) } \\
\text { *Paper straw may affect the texture } \\
\text { Plastic straw }\end{array}$ & $\begin{array}{l}\text { Please choose the bag: } \\
\text { Thermal bag } ¥ 5.00 \\
\text { Plastic bag } ¥ 0.50\end{array}$ \\
\hline
\end{tabular}

\section{Non-default condition}

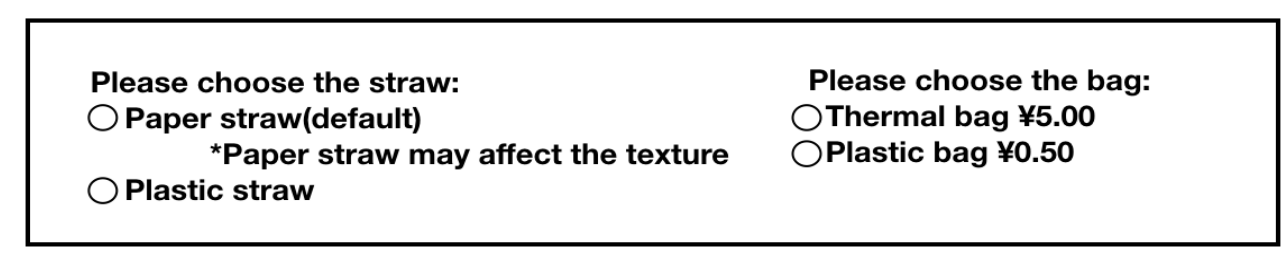

Figure 2 Choosing straw and bag under default and non-default conditions

\subsubsection{Procedure.}

The participants were recruited from Nanyue High School in Hubei. Upon consenting to their participation, the participants were randomly distributed to four conditions (disclosure $\mathrm{x}$ default, non-disclosure $\mathrm{x}$ default, disclosure $\mathrm{x}$ non-default, and non-disclosure $\mathrm{x}$ non-default) and they had received different leaflets.

After they had returned the leaflets, they received a short questionnaire with a few questions concerning the reason why they have selected the straw and the bag of their choice, and whether they have noticed the red line in the 'disclosure' condition.

\subsection{Results}

\subsubsection{Preliminary analyses.}

Before testing out the hypothesis, we conducted a preliminary test to eliminate the impact of irrelevant participant variables shown in the leaflet on the results. By conducting a chi-square test, we confirmed that the selection of beverage (a filler question to disguise the aim) in the questionnaire did not affect the following choices of straw and bag that we were majorly investigating $(\chi 2$ (straw $)=8.001, \quad \mathrm{p}=0.156)$, $\chi 2($ bag $)=2.333, \mathrm{p}=0.801, \mathrm{df}=5)$.

\subsubsection{Major analyses.}

Then, with the prerequisite that only the independent variables 'disclosure' and 'default' influenced the choices, we coded those variables in order to conduct two binary logistic regressions and verify H1-H3.

The coding for the first binary logistic regression was as follows: for independent variables, default condition $=1$, non-default condition $=-1$, disclosure condition $=1$, non-disclosure condition $=-1$; for dependent variables, selection of default paper straw $=1$, selection of plastic straw $=0$.

The coding for the second binary regression was as follows: for independent variables, default condition $=1$, non-default condition $=-1$, disclosure condition $=1$, nondisclosure condition $=-1$; for the dependent variables, selection of default cooler bag=1, selection of plastic bag $=0$. And overall there was no interaction between default and disclosure (paper straw $(B=0.046, p=0.778)$, cooler bag $(\mathrm{B}=-0.017, \mathrm{p}=0.914))$.

In the first binary logistic regression, the main effect of the default on the choice of paper straw was proved to be significant $(\mathrm{B}=0.466, \mathrm{p}=0.005)$, indicating the validation of our hypothesis one that more participants chose the paper straw when it was set as default. Similarly, the second binary logistic regression of bag selection reiterated the default effect $(B=0.580$, $\mathrm{p}<0.001$ ), thus further justifying our hypothesis one. 
In the non-hypocritical condition (straw selection), the main effect of disclosure was marginally significant in the expected positive direction according to the first binary logistic regression $(B=0.280, p=0.086)$. This means even more participants choose the default option in addition to the inherent default effect, after disclosure of the pro-environmental intention of the vendor. Therefore, we deduced that the non-hypocritical disclosure has the amplifying power on the default effect, promoting even more pro-environmental behavior, and this validated our hypothesis two.

Table 1. Major analysis

\begin{tabular}{ccccccc}
\hline & \multicolumn{3}{c}{ Straw } & & Bag & \\
\hline & S.E. & B & P value & S.E. & B & P value \\
\hline Default & 0.165 & 0.466 & 0.005 & 0.160 & 0.580 & 0.000 \\
Disclosure & 0.163 & 0.280 & 0.086 & 0.160 & 0.262 & 0.102 \\
Default x disclosure & 0.163 & 0.046 & 0.778 & 0.160 & -0.017 & 0.914 \\
\hline
\end{tabular}

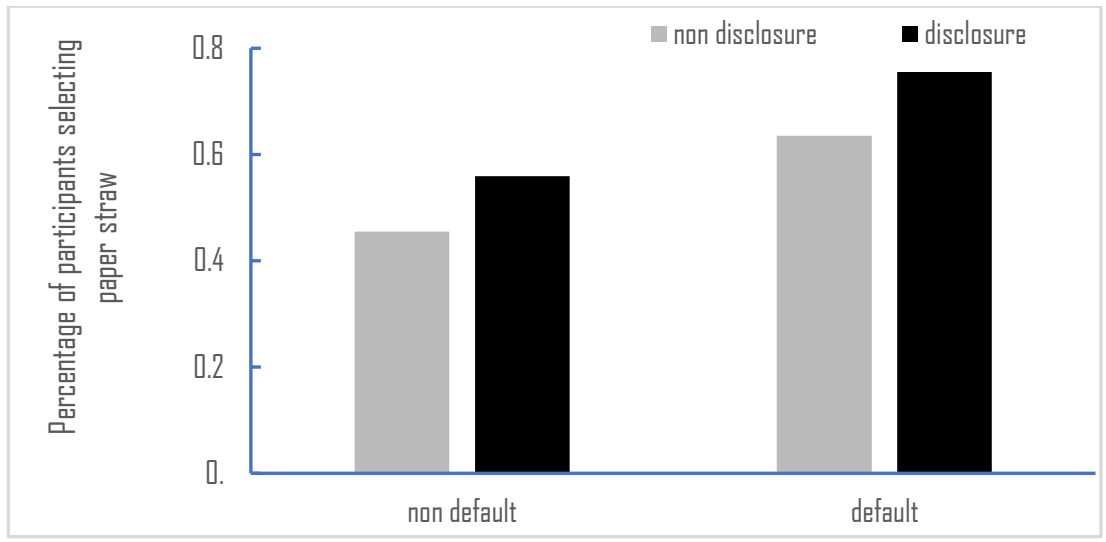

Figure 3 Selection of paper straw

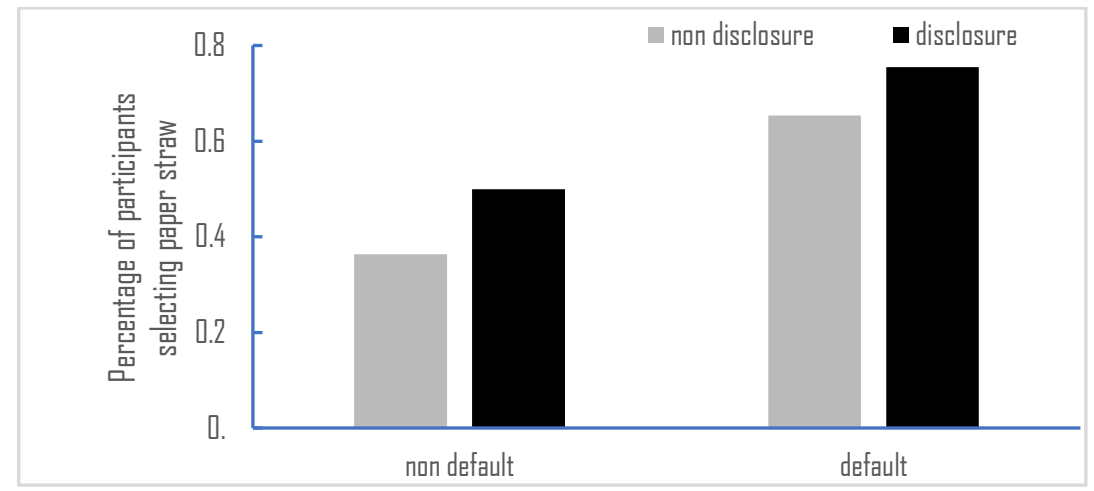

Figure 4 Selection of thermal bag

The main effect of disclosure in hypocritical (bag selection) condition was insignificant and it was in the opposite direction as expected $(\mathrm{B}=0.262, \mathrm{p}=0.102)$, which indicated that there was no backfire effect on the selection of default option and still more people chose the default option in addition to default effect when the intention was disclosed hypocritically. Therefore, hypothesis three was nullified, and the result illustrated an unexpected positive disclosure effect similar to the case of straw selection, though to a lesser extent.

\subsubsection{Further analyses.}

To further examine the reason behind the choice, we conducted other two binary logistic regressions. In these analyses, we only included the participants who had 
chosen the default option, given that we aim to investigate the rationale of the default effect and its moderators.

In the case of non-hypocritical condition, we coded independent variables similarly (default $=1$, nondefault $=-1$, disclosure $=1$, non-disclosure $=-1$ ), and dependent variables as environmental reason $=1$, other reasons $=0$. The result showed that there was no interaction of default and disclosure on reasons given by the participants $(\mathrm{B}=0.047, \mathrm{p}=0.858)$. The default main effect was significant in the negative direction $(B=-$ $0.926, \mathrm{p}<0.001$ ), which means fewer people had an environmental reason for choosing paper straw when it was set as default. On the other hand, disclosure did not significantly change the environmental concerns of participants $(\mathrm{B}=0.424, \mathrm{p}=0.108)$. This result is intriguing as it somehow buttressed the automatic processes involved in the selection of default options, which would be discussed in general discussion.

Table 2. Further analysis

\begin{tabular}{ccccccc}
\hline & \multicolumn{3}{c}{ Straw } & & \multicolumn{2}{c}{ Bag } \\
\hline & S.E. & B & P value & S.E. & B & P value \\
\hline Default & 0.264 & -0.926 & 0.000 & 0.240 & -0.240 & 0.316 \\
Disclosure & 0.264 & 0.424 & 0.108 & 0.240 & 0.817 & 0.001 \\
Default x disclosure & 0.264 & 0.047 & 0.858 & 0.240 & 0.089 & 0.710 \\
\hline
\end{tabular}

We had the same coding in the case of the hypocritical condition, to conduct the second binary logistic regression. The number of participants holding environmental reasons was low as expected (an environmentally neutral selection) when participants were not disclosed, but the number increased significantly after the hypocritical disclosure, with significant disclosure main effect on reasons $(B=0.817$, $p<0.001)$. The main effect of default $(B=-0.240$, $\mathrm{p}=0.316)$ and default-disclosure interaction $(\mathrm{B}=0.089$, $\mathrm{p}=0.710$ ) upon reasons given by participants were insignificant. Accordingly, we attempted to attribute the invalidation of hypothesis three to the disclosure main effect demonstrated here, in which participants still perceived environmental relevance regardless of the deliberate hypocritical setup. We believed that the failure in hypocrisy establishment was not a coincidence, and the rationale of this radical change of perception after disclosure would be discussed in the following section.

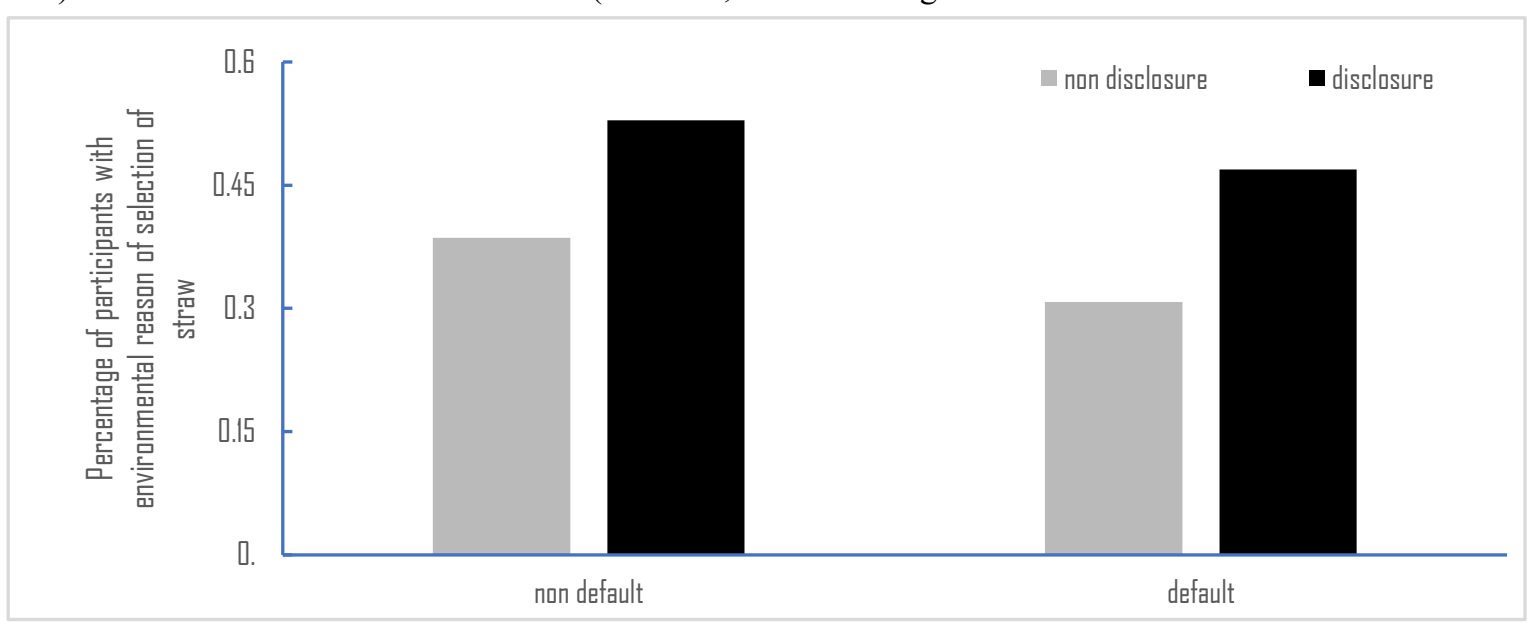

Figure 5 Environmental concerns in selecting straw 


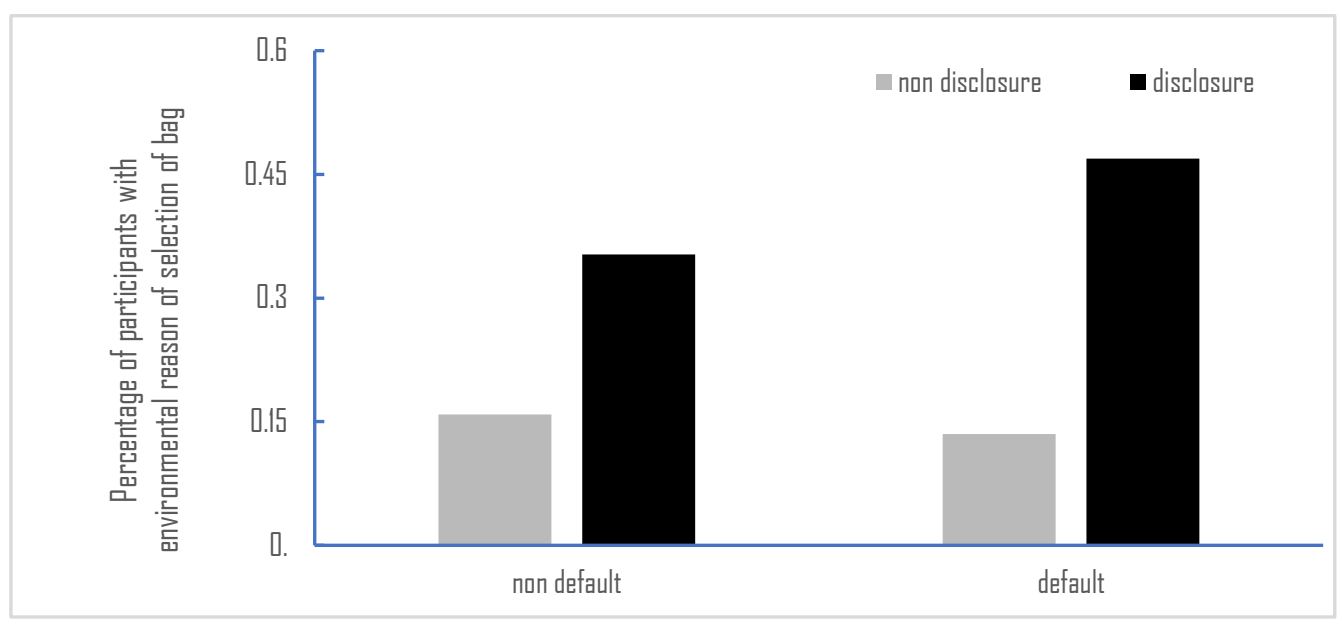

Figure 6 Environmental concerns in selecting bag

\section{DISCUSSION}

In order to investigate whether the effect of default option and disclosure exist and can hold constant across non-hypocritical and hypocritical conditions, we carried out the experiment using a milk tea purchase scenario. Our first finding was that, for both the non-hypocritical condition (paper straw vs. plastic straw) and the hypocritical condition (cooler bag vs. plastic bag), most participants stuck to the default option (i.e. the paper straw and the cooler bag). This finding is consistent with previous studies [7]-[8], which resonates with the pervasive default effect and confirms $\mathrm{H} 1$. We also found that more people stuck to the default option of paper straw in the disclosure condition than in the nondisclosure condition. This result confirmed H2. Our third finding was that more people sticked to the default option of the cooler bag in the disclosure condition than in the non-disclosure condition. This is the opposite of $\mathrm{H} 3$.

Adding onto the earlier literature, we specifically tested out the default effect among Chinese teenagers, illustrating the cross-cultural, cross-age robustness of this effect. Moreover, we replaced the commonly used laboratory setting for investigating the default effect with a real-world context that incorporates the necessary choice architectures [13], [28]. Hence the task given to participants is considered to have higher level of ecological validity. We also discern that more ecologically valid studies of the default effect often include some grand topics [7], [11], [31] and once-in-alifetime decisions. For example, some are about household energy supply while others focus on the consent of organ donation. By contrast, our study zeros in on those day-to-day trivialities, like ordering milk tea and selecting its accessories. The persistent default effect shown in our study unveils the extensive power of this nudging technique which penetrates the routine to affect our "smaller" yet more frequent decisions.
In addition to testing the presence of the default effect, we analyzed possible reasons for this skewed selection pattern to have an insight into the underlying mechanism. Counter-intuitively we discover that participants who make the pro-environmental choice (paper straw) were less likely to ascribe their behavior to environmental concerns when the choice is set as a default option, than when there's no default option. In other words, participants selecting the default are less likely to credit their behavior for environmental protection even if they in fact display such behavior. One possible reason behind this finding is that people are inclined to follow an unconscious and automatic pathway of decision-making when facing a default option [32]. According to the frameworks proposed by researchers in the field of nudging [33], many effects are ineffable by-products of intuition [34]-[35] rather than well-justified and backed up preferences. In this case, when people choose the non-hypocritical default option (paper straw) instinctively, they are less likely to contemplate a thoughtful explanation accounting for their behavior, even if that explanation is reasonable and socially desirable. Conversely, those participants in the non-default condition have no shortcut of the default option, thus they are likely to inspect the 2 options relatively more comprehensively and eventually give the pro-environmental reason corresponding to the environmental concerns provoked when they evaluate the options proactively.

Such lack of thoughtfulness induced by default setting may have certain positive implications as indicated by previous studies [36]. In this way, people take no credit for their compromise in drinking experience, so that they are less prone to the so-called "backfire anti-environmental act" mentioned by Macnaghten. This means the use of default choice architecture in the promotion of pro-environmental behavior bears very few side effects, in addition to the incomparable efficiency it affords. We name this additional bonus of default effect as the "Disclaimed 
Hero Effect" (DHE), which is generally the case when participants perform benign behavior (in this case proenvironmental) due to nudging or other implicit cognitive restructuring techniques, without the selfconsciousness of any behavioral implication and their contributions.

However, this cognitive by-product of the default effect relies heavily on its implicit nature, and the discussion above is based on the prerequisite that the default main effect is examined upon a disclosureneutral baseline. When the purpose to use the default option is disclosed, those who make the proenvironmental choice in the non-hypocritical condition would become fully aware of their behavior and accredit it instantly. Even when the context of choice-making is incongruous with the disclosure, for example in the hypocritical condition, people would still describe their behavior as pro-environmental to justify the inherent attraction of the default option.

To investigate why the participants were more likely to choose the default option of the cooler bag after disclosure, we divided the reason into two categories: pro-environmental and non-environmental. We found that more people chose pro-environmental reasons for sticking to this default option in the disclosure condition than in the non-disclosure condition. However, as mentioned before, the cooler bag is not proenvironmental, so it is interesting why the participants would explain their behavior of choosing an antienvironmental object as a pro-environmental act.

Cognitive dissonance might be one of the possible reasons. Cognitive dissonance refers to a situation in which people experience conflicts between attitudes and behaviors. This leads to an unfordable feeling, urging people to alter either their attitude or behavior to reduce such discomfort [37]. In our study, under the nondisclosure condition, there is no dissonance between participants' behavioral intention to select the cooler bag and their attitudes toward the cooler bag as no environment-related concept has been mentioned. However, in the disclosure condition, the participants are aware of the pro-environmental purpose of the default option. In this way, a certain social norm has been elicited in their mind, so they would experience dissonance between their inherent preference of a cooler bag and the idea that such a choice is against the norm. However, rather than conforming to the norm, they persuade themselves that the cooler bag is proenvironmental and they have made a pro-environmental decision. This resolution of cognitive dissonance is much easier as it is supported by the hypocritical disclosure of the vendor.

To note, different from the classic cognitive dissonance research in which people give a highly subjective evaluation of some forced-to-do laborious work, the current study gives them the chance to choose (free will), but it seems that the non-pro-environmental default option is so irresistible in this case, that they would not consider changing their selection of such option. Such a finding raises a new question: when a default option is beneficial to a certain individual but against a certain norm, will people be more likely to choose it and defend it?

Further studies are needed to replicate this study. If such a finding can be replicated, it is interesting to explore further the inner mechanisms and the boundary conditions. Whether the option is made based on a purely unconscious process or some hedonic but aware processes? Whether the pro-environmental concern is suppressed in the process of making the option but reelected in the explanation-providing phase or it provides a "filter" to select the desired information to use? Moreover, in our experiment, using the cooler bag can have certain unexchangeable benefits for some participants (keep the cold drink fresh). However, if the benefit is not so obvious (e.g. in winter or when the delivery time is shorter) or the price of the thermal bag is set to be higher, would this effect disappear and what are the turning points? Answering these questions can help us understand the possible trade-off between the mental cost to lie and disobey the norm and the individual benefit.

This finding also raises an issue in implementing a disclosure. The vendor may claim that the setting of the default option is to encourage pro-environmental behaviors, however, choosing the cooler bag which is set as the default option cannot be counted as a proenvironmental behavior because both cooler bag and plastic bag are pollutants, so default option framework aims to help the vendor make more profit instead of protecting the environment. Thus, the vendor can deceive the consumers in this way, leading to ethical issues --- the vendor is taking advantage of the consumers by cognitive tactics and disguising their real purpose. In order to prevent the vendor from deceiving the consumers, the government should supervise the vendor and make policy to punish the vendors who deceive the consumers using hypocritical disclosure of default and award the vendors who really use default options for benign pro-environmental purposes. For example, the government can make spot checks of the menu offered by those vendors who claim to use default options for pro-environmental purposes and determine whether the product set as default matches their claim and then punish or award the vendors accordingly.

Several limitations must be addressed before making the final conclusion. Firstly, the sample is limited to middle school students, who might be more prone to lofty and egalitarian values such environmental protection and be less adept in discovering the trick of the marketing professionals. This could make the participants more incline to alter their perception about 
the product under persuasion of the vendor instead of changing their behaviour of choosing the default option. Future studies should examine a wider range of participants, including those who might be less dedicated to environmental protection and be more aware of common marketing practices, to examine the robustness of cognitive dissonance in this context.

Meanwhile, the practicality of the promotion leaflet we distributed to the participants is open to question. It lacked obvious brand name, logo or introduction of the milk tea store, which made the promotion intention nebulous, provoking suspicion from participants. Moreover, we generously promised the participants a return of cash for the leftover of their 40 RMB voucher after purchasing, in order to signify the price of choices which can directly influence how much residual money they would receive. Nevertheless, it seems unreasonable for the vendor to make such an offer to the customer: while vouchers and other virtual currency specific to expenditure at the store can increase customer loyalty, offering the flexible cash allows consumers to purchase products from different competitors in the market. Therefore, the intention of our leaflet might be suspected by many participants, and the purchasing patterns demonstrated might not thoroughly reflect their actual decisions in real commercial activities. Future researches should frame the study in more realistic marketing context.

\section{CONCLUSION}

The present study found that the default proenvironmental option was preferred and this effect was further amplified by disclosing a pro-environmental intention. However, such a disclosure also promoted people to choose an anti-environmental default option, and to explain it as a pro-environmental choice, which is explicable using the theory of cognitive dissonance. We also illustrated the occurrence of "disclaimed hero effect" as a result of the automatic cognitive processes underlying the default effect. Practitioners should be alert to the possible side effects when using nudge techniques such as the default option.Further studies should be conducted to replicate the findings and explore the boundary conditions of such interesting effects.

\section{REFERENCES}

[1] P. Schultz, Strategies for Promoting Proenvironmental Behavior, European Psychologist, 19(2), 2014, pp. 107-117. DOI: https://doi.org/10.1027/1016-9040/a000163

[2] P. W. Schultz, F. G. Kaiser, Promoting proenvironmental behavior, In S. D. Clayton (Ed.), Oxford library of psychology, The Oxford handbook of environmental and conservation psychology (p. 556580), Oxford University Press, $2012 . \quad$ DOI: https://doi.org/10.1093/oxfordhb/9780199733026.0 13.0029

[3] R D Katzev, T R Johnson, Promoting energy conservation: An analysis of behavioral research, United States.

[4] J. Nolan, P. Schultz, R. Cialdini, N. Goldstein, V. Griskevicius, Normative Social Influence is Underdetected, Personality And Social Psychology Bulletin, 34(7), 2008, pp. 913-923. DOI: https://doi.org/10.1177/0146167208316691

[5] M. Şükrü Akdoğan, B. Altuntaş, Covert Marketing Strategy and Techniques, Procedia - Social And Behavioral Sciences, 207, 2015, pp. 135-148. DOI: https://doi.org/10.1016/j.sbspro.2015.10.162

[6] M. Fowlie, C. Wolfram, P. Baylis, C. Spurlock, A. Todd-Blick, P. Cappers, Default Effects And Follow-On Behaviour: Evidence From An Electricity Pricing Program, The Review Of Economic Studies, 2021. DOI: https://doi.org/10.1093/restud/rdab018

[7] E. Johnson, D. Goldstein, Do Defaults Save Lives? Science, 302(5649), 2003, pp. 1338-1339. DOI: https://doi.org/10.1126/science.1091721

[8] E. Johnson, R. Hassin, T. Baker, A. Bajger, G. Treuer, Can Consumers Make Affordable Care Affordable? The Value of Choice Architecture, PLoS ONE, 8(12), 2013. DOI:

https://doi.org/10.1371/journal.pone.0081521

[10] J. Araña, C. León, Can Defaults Save the Climate? Evidence from a Field Experiment on Carbon Offsetting Programs. Environmental And Resource Economics, 54(4), 2012, pp. 613-626. DOI: https://doi.org/10.1007/s10640-012-9615-x

[11] D. Pichert, K. Katsikopoulos, Green defaults: Information presentation and pro-environmental behaviour, Journal Of Environmental Psychology, 28(1), 2008, pp. 63-73. DOI: https://doi.org/10.1016/j.jenvp.2007.09.004

[12] C. Schubert, Green nudges: Do they work? Are they ethical?, Ecological Economics, 132, 2017, pp. 329-342. DOI: https://doi.org/10.1016/j.ecolecon.2016.11.009

[13] I. Dinner, E. Johnson, D. Goldstein, K. Liu, Partitioning default effects: Why people choose not to choose. Journal Of Experimental Psychology: Applied, 17(4), 2011, pp. 332-341. DOI: https://doi.org/10.1037/a0024354 
[14] C. Russell, M. Belch, A Managerial Investigation into the Product Placement Industry, Journal Of Advertising Research, 45(01), 2005, pp. 73. DOI: https://doi.org/10.1017/s0021849905050038

[15] D. Sprott, The Policy, Consumer, and Ethical Dimensions of Covert Marketing: An Introduction to the Special Section, Journal Of Public Policy \& Marketing, 27(1), 2008, pp. 4-6. DOI: https://doi.org/10.1509/jppm.27.1.4

[16] A. Kaikati, J. Kaikati, Stealth Marketing: How to Reach Consumers Surreptitiously, California Management Review, 46(4), 2004, pp. 6-22. DOI: https://doi.org/10.2307/41166272

[17] M. Campbell, When Attention-Getting Advertising Tactics Elicit Consumer Inferences of Manipulative Intent: The Importance of Balancing Benefits and Investments, Journal Of Consumer Psychology, 4(3), 1995, pp. 225-254. DOI: https://doi.org/10.1207/s15327663jcp0403_02

[18] G. Milne, A. Rohm, S. Bahl, If It's Legal, Is It Acceptable?, Journal Of Advertising, 38(4), 2009, pp. 107-122. DOI: https://doi.org/10.2753/joa00913367380408

[19] G. Xie, D. Boush, R. Liu, Tactical deception in covert selling: A persuasion knowledge perspective, Journal Of Marketing Communications, 21(3), 2013, pp. 224-240. DOI: https://doi.org/10.1080/13527266.2012.754369

[20] C. Wortman, J. Brehm, Responses to Uncontrollable Outcomes: An Integration of Reactance Theory and the Learned Helplessness Model, Advances In Experimental Social Psychology, 1975, pp. 277-336. DOI: https://doi.org/10.1016/s0065-2601(08)60253-1

[21] H. Bang, S. Shu, E. Weber, The role of perceived effectiveness on the acceptability of choice architecture, Behavioural Public Policy, 4(1), 2018, pp. 50-70. DOI: https://doi.org/10.1017/bpp.2018.1

[22] J. Reynolds, S. Archer, M. Pilling, M. Kenny, G. Hollands, T. Marteau, Public acceptability of nudging and taxing to reduce consumption of alcohol, tobacco, and food: A population-based survey experiment, Social Science \& Medicine, 2019, pp. $236 . \quad$ DOI: https://doi.org/10.1016/j.socscimed.2019.112395

[23] S. Davidai, E. Shafir, Are "Nudges" Getting a Fair Shot? Joint Versus Separate Evaluation, Behavioural Public Policy, 4(3), 2018, pp. 273291. DOI: https://doi.org/10.1017/bpp.2018.9

[24] M. Friestad, P. Wright, The Persuasion Knowledge Model: How People Cope with Persuasion
Attempts. Journal Of Consumer Research, 21(1), 1994, pp. 1. DOI: https://doi.org/10.1086/209380

[25] M. Campbell, When Attention-Getting Advertising Tactics Elicit Consumer Inferences of Manipulative Intent: The Importance of Balancing Benefits and Investments, Journal Of Consumer Psychology, 4(3), 1995, pp. 225-254. DOI: https://doi.org/10.1207/s15327663jcp0403_02

[26] C. Pechmann, L. Wang, Effects of Indirectly and Directly Competing Reference Group Messages and Persuasion Knowledge: Implications for Educational Placements, Journal Of Marketing Research, 47(1), 2010, pp. 134-145. DOI: https://doi.org/10.1509/jmkr.47.1.134

[27] M. Wei, E. Fischer, K. Main, An Examination of the Effects of Activating Persuasion Knowledge on Consumer Response to Brands Engaging in Covert Marketing, Journal Of Public Policy \& Marketing, 27(1), 2008, pp. 34-44. DOI: https://doi.org/10.1509/jppm.27.1.34

[28] C. Brown, A. Krishna, The Skeptical Shopper: A Metacognitive Account for the Effects of Default Options on Choice, Journal Of Consumer Research, 31(3),2004, pp. 529-539. DOI: https://doi.org/10.1086/425087

[29] D. Pichert, K. Katsikopoulos, Green defaults: Information presentation and pro-environmental behaviour, Journal Of Environmental Psychology, 28(1), 2008, pp. 63-73. DOI: https://doi.org/10.1016/j.jenvp.2007.09.004

[30] A. Abid, P. Harrigan, An Exploration of Social Media- Enabled Voter Relationships through uses and Gratifications Theory, Psychological Contract and Service-Dominant Orientation, Australasian Marketing Journal, 28(2), 2020, pp. 71-82. DOI: https://doi.org/10.1016/j.ausmj.2020.02.002

[31] J. Choi, D. Laibson, B. Madrian, A. Metrick, "For Better or for Worse: Default Effects and 401(k) Savings Behavior," NBER Chapters, in Perspectives on the Economics of Aging, National Bureau of Economic Research, Inc. 2004, pp. 81126

[32] A. Lopez-Persem, P. Domenech, M. Pessiglione, How prior preferences determine decision-making frames and biases in the human brain, Elife, 5, 2016. DOI: https://doi.org/10.7554/elife.20317

[33] F. Ölander, J. Thøgersen, Informing Versus Nudging in Environmental Policy, Journal Of Consumer Policy, 37(3), 2014, pp. 341-356. DOI: https://doi.org/10.1007/s10603-014-9256-2 
[34] D. Kahneman, J. Knetsch, R. Thaler, Anomalies: The Endowment Effect, Loss Aversion, and Status Quo Bias, Journal Of Economic Perspectives, 5(1), 1991, pp. 193-206. DOI: https://doi.org/10.1257/jep.5.1.193

[35] N. Smith, D. Goldstein, E. Johnson, Choice without Awareness: Ethical and Policy Implications of Defaults, Journal Of Public Policy \& Marketing, 32(2), 2013, pp. 159-172. DOI: https://doi.org/10.1509/jppm.10.114
[36] P. Macnaghten, J. Urry, Towards a Sociology of Nature, Sociology, 29(2), 1995, pp. 203-220. DOI: https://doi.org/10.1177/0038038595029002002

[37] A. Pepitone, L. Festinger, A Theory of Cognitive Dissonance, The American Journal Of Psychology, 72(1), 1959, pp. $153 . \quad$ DOI: https://doi.org/10.2307/1420234 